\title{
Psychotherapy Integration: A main Obstacle and Challenge
}

\section{La Integración en Psicoterapia: Un Obstáculo y Desafío Principal}

\author{
Isabel Caro \\ University of Valencia, Faculty of Psychology, Department of Personality, Assessment and \\ Psychological Treatments, España
}

Rec (15 de septiembre de 2017) Acept (12 de octubre de 2018)

\begin{abstract}
Psychotherapy integration is a key trend in psychotherapy nowadays. This paper offers a critical perspective on a main obstacle and challenge for psychotherapy integration. Psychotherapy integration should be treated more as a process than as a product. For psychotherapy integration to contribute to the future of psychotherapy, it should not forget its original Exploratory spirit, avoiding and being cautious about Established approaches, and being, therefore, more a process than a product. This assumption should be related first with the core spirit of psychotherapy integration, an ongoing process of respect for different psychotherapeutic models, and an attitude of work in progress. It should, secondly, be related with the stance or perspective that ought to be taken toward the ongoing appearance of new integrative models.

Key words: psychotherapy integration; integrative models; single-orientation; psychotherapy
\end{abstract}

\section{Resumen}

La tendencia actual a la integración en psicoterapia es importante. Este trabajo plantea una perspectiva crítica sobre un obstáculo y desafío principal para dicha tendencia. La integración en psicoterapia debe tratarse más como un proceso que como un producto. Para que la integración en psicoterapia contribuya al futuro de la psicoterapia no debería olvidar su espíritu inicial de Exploración, evitando y tomando precauciones frente a los enfoques Establecidos, convirtiéndose, por tanto, más en un proceso que en un producto. Este supuesto se puede relacionar, en primer lugar, con el espíritu central de la integración en psicoterapia, es decir, con un proceso continuo de respeto de los distintos enfoques psicoterapéuticos, y una actitud de trabajo en progreso. En segundo lugar, se puede relacionar con la perspectiva que se debe asumir en relación a la aparición continua de nuevos modelos integradores.

Palabras clave: integración en psicoterapia; modelos integradores; orientación única; psicoterapia 


\section{Introduction}

Nowadays the psychotherapy field is complex, and is characterized by multiple approaches and by different therapeutic trends. Psychotherapy integration is one of those trends. It was established more than 30 years ago (see a review in Goldfried, Pachankis \& Bell, 2005) and has evolved from being a promise to being a relevant perspective and a movement (Norcross \& Goldfried, 2005).

The reasons for integration are various and diverse (see Norcross, 2005; Norcross \& Newman, 1992), e.g., the large number of approaches, the recognition that there are no differences in efficacy between models, or that no given model covers the whole "territory". Other conditions are several socio-political and economic factors that imply looking for better and improved models; the development of a professional network (SEPI, or Society for the Exploration of Psychotherapy Integration) and its corresponding journal (Journal of Psychotherapy Integration), etc.

The tendency toward integration is characterized by the intent to look for convergences and communalities between different therapeutic perspectives. In the background, there is a relevant element to judge the contribution of psychotherapy integration, respect for already established models. Psychotherapy integration has not only introduced this attitude into the psychotherapy field. One main consequence of this perspective is also the appearance of integrative models.

Psychotherapy integration has been developed around four main tendencies; i.e.,common factors, technical eclecticism, theoretical integration and assimilative integration (Norcross, 2005). However, this paper focuses only on psychotherapy integration as a main tendency, and on what could be its main contribution to the psychotherapy field and what can impede it.

For psychotherapy integration to contribute to this field, a critical stance is needed; i.e., a perspective focused mainly on what could presently be both a main obstacle and challenge for psychotherapy integration. The main issue to be emphasized is that the tendency toward integration, along with any integrative model, should be treated as a process, not as a product. The reasons are twofold and interconnected. First, because it concurs with the core spirit of psychotherapy integration, an ongoing process of openness and respect toward other psychotherapeutic models, an ever-progressing work (Stricker, 2010). Second, because it is important to maintain and defend that spirit before the ongoing development of new integrative models in a complex field characterized by the high multiplicity of approaches.

Resolving how to treat integration and integrative approaches could mark the development, permanence and promise of psychotherapy integration.

\section{What does to integrate mean?}

From the very beginning, psychotherapy integration has made it clear that to integrate implies acknowledging the inadequacies of a specific model and to respect others' potential contributions (Norcross, 2005). As FernándezÁlvarez et al. (2016, p. 820) emphasize, psychotherapy integration "invites dialogue and exploration, as well as a commitment to ongoing developments and processes, rather than end-goals in facilitating the evolution of psychotherapy.... Psychotherapy integration characterizes and ongoing rapprochement, convergence, and complementarity"... at the conceptual, clinical and empirical levels.

\section{The main psychotherapy integration spirit}

Psychotherapy integration has always favored a clear respectful attitude toward other models. An integrative therapist defends the common sense perspective that things are better appreciated and understood from different angles (Gaete \& Gaete, 2015). A key characteristic of an integrative therapist is that of taking an attitude of respect, open-mindedness, avoiding partisan fights, and feeling comfortable with multiple therapeutic voices.

This spirit, that the tendency toward integration tended to enlarge, was not alien to the psychotherapeutic field (see a review in Norcross, 2005). For instance, Luborsky, Singer \& Luborsky (1975), based on Rosenzweig (1936), defended the Dodo bird verdict in Alice in Wonderland, "everybody has won and all must have prizes". This spirit is one of the main appeals of psychotherapy integration and one that should never be forgotten or discarded for psychotherapy integration to survive, to make its promises possible. This spirit is especially related to the place of integrative models, among other psychotherapeutic approaches.

\section{Psychotherapy integration and its relationship with other models}

Placing integrative models among other approaches makes it harder to defend psychotherapy integration as an ongoing process, and easier to consider it a product. Thus, psychotherapy integration maintains a complicated relationship with other models and tendencies. In particular, the relationship between "pure models", or singleorientations, and integrative ones is complex (DiMaggio \& Lysaker, 2014; Govrin, 2014; Wachtel, 2014).

No psychotherapeutic model could offer a whole account of the field, and all models evolve and improve with the passing of time. In addition, it seems obvious to acknowledge that no model emerges ex nihilo. Any psychotherapeutic model will have arisen as an "integrative" one by taking 
what is available in an attempt to improve it. An integrative model also tends to integrate whatever is in the field; i.e., unavoidably, psychotherapy integration tends to depend on other already established models (Norcross, 2005) that offer the basis for integration and improvement. The ongoing quest of integration aims to offer a better model based on the best available evidence. So what should be the treatment of these integrative models?

Obviously, it can be assumed that any proponent of a new model defends it by emphasizing its uniqueness and main advantages. Unfortunately, however, a striking resemblance could exist between how a "pure model" and an integrative one could be introduced. Integrationist proponents commonly acknowledge that excessive dogmatism or ideological and partisan zeal is characteristic of the defense of some pure models (Safran \& Messer, 1997). This assumption, which could regrettably be accurate in many forums, indicates an obstacle that hinders respect for, and the defense of, plural perspectives. Consequently, psychotherapeutic practice could deteriorate instead of being improved (Castonguay, 2011).

Therefore, problems exist when integration is defended as aspiring to be an overarching approach. This could be deducted from the following passage, taken as an example: "As applied to psychotherapy, "integration" refers to harmoniously bringing together affective, cognitive, behavioral, and systems approaches to psychotherapy under the roof of one theory, and applying this theory and associated techniques to the treatment of an individual, couple, or family" (Beutler, Harwood \& Caldwell, 2001, p. 143). More than 30 years of integration has not provided such an overarching model. Therefore, looking for such a model could be considered one of the main obstacles and a present challenge for psychotherapy integration to survive and to contribute to the psychotherapy field.

\section{Discussion: Obstacles and challenges to psychotherapy integration: What does psychotherapy integration not mean?}

If some attitudes are problematic for proponents of "pure models", as Safran and Messer assumed (1997), they might also be considered the opposite to the psychotherapy integration spirit, which can prove even more problematic. More importantly, this could interfere with treating psychotherapy integration as a process. Exactly as when other models arise, it is advisable to follow a respectful and open-minded spirit when an integrative perspective is developed, and the relevance of integration for the psychotherapy status and future is defended. However, when the spirit of Exploration is forgotten by defending a single Established approach (Stricker, 2010) there is no psycho- therapy integration. The defense of models with partisan zeal, regardless of them being integrative or not, does not favor psychotherapy integration. If there is a quest for The or $A n$ integrative model, this is similar to the mistake other approaches have made which place themselves in a position from which they can only see their own versions of reality and truth, and promote them (Gelso, 2009), and hence this is not psychotherapy integration.

One remarkable example of this, and one that is contrary to the psychotherapy integration spirit (see Stricker, 2010), could be seen in the assumption that cognitive therapy (and cognitive-behavioral therapy) could be a main integrative approach (Alford \& Norcross, 1991; Beck, 1991). One of the main reasons lies in the defense of cognitive change as a common factor for all psychotherapeutic models. However, one thing is to defend a common and relevant factor, and another quite different one is to consider a model "a main integrative" model.

This assumption could exemplify some main tenets of this Discussion. First, because if we collapse psychotherapeutic models under just one heading, or under just one common factor, this goes against the psychotherapy integration spirit. Simply, the focus on psychotherapeutic change and main elements could not neglect behavioral, emotional, affective, nor cognitive factors. To see change under just one lens goes against scientific evidence (Kazdin, 2007). Accordingly, this supports the defense of and contribution to psychotherapy of different perspectives and focuses.

Secondly, because looking for one model separates psychotherapy integration from its prospective and main contribution to psychotherapy. As previously stated, the quest for an integrative model (i.e., for a product) will not favor psychotherapy integration and will not sustain its specific contribution.

Therefore, focusing mistakenly on psychotherapy integration more as a product than as an attitude and a process (Stricker, 2010; Wachtel, 2014) does not favor psychotherapy integration. This is one of the major obstacles and challenges for today's psychotherapy integration, and a reflection that it is almost missing in this field. That is, paradoxically, the ongoing quest for integrative models could render the tendency toward integration problematic. Psychotherapy integration partly justified its appearance by the excessive amount of psychotherapeutic approaches. Contradictorily, offering new and integrative models contributes to the same problems they wanted to overcome. If psychotherapy integration is a product, and not an attitude and a process, it will always be found in the psychotherapy field as another model by offering more approaches to the field, which will be added to already available ones. Then its original impetus will be deluded. In other words, it will be treated as another model that will co-exist with the main ones (Mahoney, 1995). 


\section{Conclusion}

To conclude, psychotherapy integration should be an ongoing quest, process and work in progress and, therefore, should always be a model that facilitates and defends the exploration, co-existence, respect and acknowledgment of different therapeutic approaches. This original integrative spirit makes more for the future of psychotherapy than the development of "another model". Finally, the main suggestion made is that the respect for variability and co-existence are key. Therefore, here relies the debt with the core elements and reasons behind psychotherapy integration.

\section{References}

Alford, B.A. \& Norcross, J.C. (1991). Cognitive therapy as integrative therapy. Journal of Psychotherapy Integration, 1, 175-190.

Beck, A .T. (1991). Cognitive therapy as the integrative therapy. Journal of Psychotherapy Integration, 1, 191-198.

Beutler, L. E., Harwood, T. M. \& Caldwell, R. (2001). Cognitive-behavioral therapy and psychotherapy integration. In K.S. Dobson (Ed.), Handbook of cognitive-behavioral therapies (pp. 138-170). New York: Guilford Press.

Castonguay, L. G. (2011). Psychotherapy, psychopathology, research and practice: Pathways of connections and integration. Psychotherapy Research, 21, 125-140. doi: 10.1080/10503307.2011.563250

Dimaggio, G. \& Lysaker, P.H. (2014). Supporters of a single orientation may do less for science and the health of patients than integrationists: A reply to Govrin (2014). Journal of Psychotherapy Integration, 24, 91-94. http://dx.doi.org/ 10.1037/ a0036996

Fernández-Álvarez, H., Consoli, A. J. \& Gómez, B. (2016). Integration in psychotherapy: Reasons and challenges. American Psychologist, 71, 820-830. http://dx.doi.org/10.1037

Gaete, A. \& Gaete, J. (2015). On theoretical integration in psychotherapy. Journal of Psychotherapy Integration. 25, 158-174. http://dx.doi. org/10.1037/a0038883

Gelso, C. J. (2009). Confessions of a non-believer: The merits and mythology of integration. Applied and Preventive Psychology, 13, 14-15. doi: 10.1016/j.appsy.2009.10.007

Goldfried, M. R., Pachankis, J. E. \& Bell, A.C. (2005). A history of psychotherapy integration. In J. C. Norcross \& M. R. Goldfried (Eds.) Handbook of psychotherapy integration (2 ed.) (pp. 3-23). New York: Oxford University Press.

Govrin, A. (2014). The vices and virtues of monolithic thought in the evolution of psychotherapy. Journal of Psychotherapy Integration, 24, 79-90. http://dx.doi.org/10.1037/a0035972

Kazdin, A. E. (2007). Mediators and mechanisms of change in psychotherapy research. Annual Review of Clinical Psychology, 3, 1-27. doi: 10.1146/annurev.clinpsy. 3.022806.091432

Luborsky, 1., Singer, B. \& Luborsky, L. (1975). Comparative studies of psychotherapy: Is it true that "everybody has won and all must have prizes"? Archives of General Psychiatry, 32, 995-1008.

Mahoney, M. J. (1995). The modern psychotherapist and the future of psychotherapy. In B. Bongar \& L. E. Beutler (Eds.), Comprehensive textbook of psychotherapy (pp.474-488). New York: Oxford University Press.

Norcross, J. C. (2005). A primer on psychotherapy integration. In J. C. Norcross \& M. R. Goldfried (Eds.) Handbook of psychotherapy integration (2 ed.) (pp. 3-23). New York: Oxford University Press.

Norcross, J. C. \& Goldfried, M.R. (2005). The future of psychotherapy integration: A roundtable. Journal of Psychotherapy Integration, 15, 392-471. doi: 10.1037/1053-0479.15.4.392

Norcross, J. C. \& Newman, C.F. (1992). Psychotherapy integration: Setting the context. In J.C. Norcross \& M.R. Goldfried (Eds.), Handbook of psychotherapy integration (pp. 3-45). New York: Basic Books.

Rosenzweig, S. (1936). Some implicit common factors in diverse methods in psychotherapy. "At last the Dodo said, "Everybody has won and all must have prizes." American Journal of Orthopsychiatry, 6, 412-415.

Safran, J. D. \& Messer, S.B. (1997). Psychotherapy integration: A postmodern critique. Clinical Psychology: Science \& Practice, 4, 140-152.

Stricker, G. (2010). A second look at psychotherapy integration. Journal of Psychotherapy Integration, 20, 397-405. http://dx.doi.org/10.1037/ a0022037

Wachtel, P. L. (2014). On the limits of theoretical fundamentalism. Journal of Psychotherapy Integration, 24, 95-98. http://dx.doi.org/10.1037/ a0036973 